\title{
Article \\ Serum sCD25 Protein as a Predictor of Lack of Long-Term Benefits from Immunotherapy in Non-Small Cell Lung Cancer: A Pilot Study
}

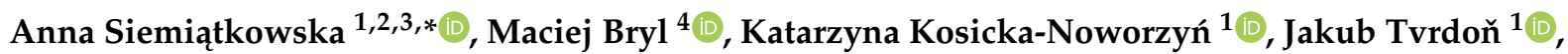 \\ Iwona Gołda-Gocka ${ }^{4}$, Aleksander Barinow-Wojewódzki ${ }^{4}$ and Franciszek K. Główka ${ }^{1}$ (D) \\ 1 Department of Physical Pharmacy and Pharmacokinetics, Poznan University of Medical Sciences, \\ 6 Święcickiego Street, 60-781 Poznań, Poland; kasiakosicka@ump.edu.pl (K.K.-N.); \\ jakub.tvrdon.pl@gmail.com (J.T.); glowka@ump.edu.pl (F.K.G.) \\ 2 Department of Pharmaceutics, Ernest Mario School of Pharmacy, Rutgers, The State University of New Jersey, \\ 160 Frelinghuysen Road, Piscataway, NJ 08854, USA \\ 3 Center of Excellence for Pharmaceutical Translational Research and Education, Ernest Mario School of \\ Pharmacy, Rutgers, The State University of New Jersey, 160 Frelinghuysen Road, Piscataway, NJ 08854, USA \\ 4 Department of Clinical Oncology with the Subdepartment of Diurnal Chemotherapy, Wielkopolska Center of \\ Pulmonology and Thoracic Surgery, 62 Szamarzewskiego Street, 60-569 Poznań, Poland; \\ mbryl@wcpit.org (M.B.); agocki@wp.pl (I.G.-G.); awojewodzki@wcpit.org (A.B.-W.) \\ * Correspondence: asiemiatkowska@ump.edu.pl
}

Citation: Siemiątkowska, A.; Bryl, M.; Kosicka-Noworzyń, K.; Tvrdoň, J.; Gołda-Gocka, I.; Barinow-Wojewódzki, A.; Główka, F.K. Serum sCD25 Protein as a Predictor of Lack of Long-Term Benefits from Immunotherapy in Non-Small Cell Lung Cancer: A Pilot Study. Cancers 2021, 13, 3702. https://doi.org/10.3390/cancers 13153702

Academic Editors: Julien Péron and Amélie Boespflug

Received: 13 June 2021

Accepted: 21 July 2021

Published: 23 July 2021

Publisher's Note: MDPI stays neutral with regard to jurisdictional claims in published maps and institutional affiliations.

Copyright: (c) 2021 by the authors. Licensee MDPI, Basel, Switzerland. This article is an open access article distributed under the terms and conditions of the Creative Commons Attribution (CC BY) license (https:/ / creativecommons.org/licenses/by/ $4.0 /)$.
Simple Summary: The prognosis of advanced lung cancer is poor. Even though it can improve with immunotherapy, most patients do not respond to treatment. Identifying patients who would not benefit from therapy is an unmet goal. We hypothesized that one of the molecules present in human serum (namely, the soluble form of the unit $\alpha$ of the interleukin- 2 receptor, sCD25) could be used as a predictor of successful immunotherapy in patients with lung cancer. Our study showed that patients who presented high sCD25 levels before treatment $(\geq 5.99 \mathrm{ng} / \mathrm{mL})$ and /or about three months from the start of treatment $(\geq 7.73 \mathrm{ng} / \mathrm{mL})$ progressed faster and lived shorter without the disease progression and serious toxicity. Serum levels of sCD25 could easily indicate patients with lung cancer who would not achieve long-term benefits from immunotherapy. Therefore, other more effective therapies could be implemented.

Abstract: Prognosis of advanced non-small cell lung carcinoma (NSCLC) is poor. Even though it can improve with anti-PD-1/PD-L1 agents, most patients do not respond to treatment. We hypothesized that the serum soluble form of the unit $\alpha$ of the interleukin-2 receptor (sCD25) could be used as a biomarker of successful immunotherapy in NSCLC. We recruited patients dosed with atezolizumab $(n=42)$ or pembrolizumab $(n=20)$ and collected samples at baseline and during the treatment. Levels of sCD25 were quantified with the ELISA kits. Patients with a high sCD25 at baseline $(\mathrm{sCD} 25.0 \geq 5.99 \mathrm{ng} / \mathrm{mL})$ or $/$ and at the end of the fourth treatment cycle $(\mathrm{sCD} 25.4 \geq 7.73 \mathrm{ng} / \mathrm{mL}$ ) progressed faster and lived shorter without the disease progression and serious toxicity. None of the patients with high sCD25 at both time points continued therapy longer than 9.3 months, while almost $40 \%$ of patients with low sCD25 were treated for $\geq 12.3$ months. There was a 6.3-times higher incidence of treatment failure ( $\mathrm{HR}=6.33,95 \% \mathrm{CI}: 2.10-19.06, p=0.001)$ and a 6.5-times higher incidence of progression ( $\mathrm{HR}=6.50,95 \% \mathrm{CI}: 2.04-20.73, p=0.002)$ in patients with high compared with low sCD25.0 and sCD25.4. Serum levels of sCD25 may serve as a non-invasive biomarker of long-term benefits from the anti-PD-1/PD-L1s in NSCLC.

Keywords: biomarkers; sCD25; atezolizumab; pembrolizumab; anti-PD-1/PD-L1 


\section{Introduction}

Non-small-cell lung carcinoma (NSCLC) comprises $80-85 \%$ of all lung cancers. Usually, there are no symptoms until the disease is at an advanced stage. Thus, diagnosis is often late [1]. The five-year survival of lung cancer patients in Europe between 1999 and 2007 was about 13\% [2], while in the U.S., it was about $17 \%$ in 2009 [3]. The introduction of immune-checkpoint inhibitors (ICIs) reduced the mortality rate by approx. 30\% [4]. However, the response rates are still below expectations. Depending on the subset of NSCLC patients, the highest observed overall response rates (ORRs) range between 30 and $40 \%$ [5-8]. Importantly, some patients benefit from treatment only temporarily [9,10]. Thus, non-responders, short-term responders, and long-term survivors can be distinguished among patients dosed with the ICIs [11].

The programmed cell death protein 1 (PD-1) receptor, or its ligand 1 (PD-L1) directed agents became crucial in the treatment of NSCLC including atezolizumab (ATEZO), nivolumab (NIVO), and pembrolizumab (PEMBRO) $[4,8]$. They inhibit the interaction between PD-1 (located on T cells) and PD-L1 (expressed by tumor cells). Such an action prevents the immune response inhibition and blocks the mechanism used by tumor cells to evade the immune eradication [12]. A correlation between PD-L1 tumor expression and overall survival (OS) or progression-free survival (PFS) has been established [6] and, up to now, PD-L1 expression is the only biomarker used in clinical practice for patients qualification for ICI therapy. However, several clinical trials have shown that patients with no PD-L1 tumor expression also benefited from immunotherapy $[7,13]$. Based on the PD-L1 expression, it is impossible to indicate which patients would not benefit from therapy [5]. The predictive power of PD-L1 is limited by the heterogeneity of its expression within the tumor tissue and the diversity of antibodies used in the assays $[5,14,15]$.

Great emphasis is being placed on understanding why only a subset of patients responds to immunotherapy. Efforts are being made to develop a panel of biomarkers that could identify patients that would most likely benefit from ICIs [16]. Recent meta-analyses have shown that particularly useful in this field could be tumor mutation burden [17] and neutrophil-to-lymphocyte ratio [18] that impacted both OS and PFS in NSCLC patients treated with ICIs.

Several soluble proteins have been identified to correlate with immune activation, (e.g., a soluble form of the unit $\alpha$ of interleukin-2 (IL-2) receptor, called sCD25 or sIL-2R $\alpha$ ) [19]. The sCD25 was postulated as a surrogate marker of T-cell activation and the indicator of subsequent cellular death [20]. The exact role of sCD25 in immunity and tolerance mechanisms remains unclear, as summarized recently by Damoiseaux [21]. One of the hypotheses concerning the function of sCD25 says that it could act as a decoy receptor for IL-2, resulting in reduced bioavailability of IL-2. An intermediate-affinity dimeric receptor (units $\beta$ and $\gamma$ ) expressed by NK-cells and conventional T-cells would then lose the competition for IL-2 with a high-affinity tri-molecular receptor (units $\alpha, \beta$, and $\gamma$ ) expressed by regulatory T cells (Tregs). As a consequence, tolerance induction would be favored over the activation of T-cell responses [21].

The elevated levels of serum sCD25 (sIL-2R) have been linked with poor outcomes in various blood [22,23] and solid cancers [24-27], including NSCLC [28-30]. Cabrera and colleagues $[25,31]$ observed the elevated levels of sCD25 in hepatocellular carcinoma and postulated sCD25 as a mediator of T-cell suppression and tumor progression. Due to their mechanism of action, ICIs-based drug regimens also started to be investigated for their efficacy in relation to the sCD25 levels. An in vitro study showed that sCD25 protein inhibited the antitumor effects of cytotoxic T lymphocyte antigen-4 (CTLA-4) blockade [32] Accordingly, higher baseline sCD25 predicted shorter OS in metastatic melanoma patients administered with different anti-CTLA-4 agents [32,33].

Currently, there are no data regarding SCD25 levels in NSCLC patients treated with ICIs. This study aimed to assess the possible utility of sCD25 in lung cancer as an early indicator of the long-lasting benefits and durable responses to the anti-PD-1/PD-L1 agents. 
We assessed the protein levels in sera of patients with advanced NSCLC, both at the initiation of the therapy with ATEZO or PEMBRO and during subsequent doses.

\section{Materials and Methods}

\subsection{Study Population}

This study included 62 individuals with advanced NSCLC, qualified to the national drug program (Supplementary Table S1) and treated with ATEZO $(n=42)$ or PEMBRO $(n=20)$ in the Eugenia and Janusz Zeyland Wielkopolska Center of Pulmonology and Thoracic Surgery in Poland. Patients received the drug in monotherapy as a first-line (PEMBRO; $200 \mathrm{mg}$ Q3W) or a second-line treatment (ATEZO; $1200 \mathrm{mg}$ Q3W). We recruited patients before their first anti-PD-1/PD-L1 administration and asked them to provide five blood samples, the first one at enrollment (baseline; sample taken just before the first dose of ICI), and the next samples in three-week intervals, just before administrating the consecutive doses of ICI (the last sample was taken at the end of cycle four, just before administrating the fifth dose). Immunotherapy was continued until unacceptable toxicity, disease progression, or death. Each patient filled out a questionnaire on anthropometric measurements, general health, and smoking habits.

Response to treatment was assessed every three months according to the Response Evaluation Criteria in Solid Tumors (RECIST, version 1.1) [34], and was classified as complete response (CR), partial response (PR), stable disease (SD), or progressive disease (PD). Patients with PD were no longer eligible for immunotherapy and stopped receiving the anti-PD-1/PD-L1s. Each patient who continued therapy was followed up for at least twelve months from the start of treatment. Clinical benefits (disease control) were defined as obtaining SD, PR, or CR and objective response (OR) as obtaining PR or CR. PFS was measured as the time from the initiation of therapy to confirmed progression (PD or death); time to treatment failure (TTF) as the time from the initiation of therapy to its discontinuation; and OS as the time from the start of therapy to death.

BMI and smoking status were calculated based on the self-reported data; never smokers were defined as patients who smoked $<100$ cigarettes in their lifetime, and former/current smokers as patients who smoked $\geq 100$ cigarettes and had quit smoking (former smokers) or smoked cigarettes (current smokers) at the time of the interview [35].

Table 1 presents the detailed characteristics of the study population. Thirteen out of sixtytwo patients (21.0\%) were still on treatment at the time of data cut-off (TTF $\geq 12.9$ months). After a minimum follow-up of twelve months, the ORR was $16.1 \%$. Half of the patients discontinued therapy within 5.7 months from the start of treatment (Supplementary Figure S1A), and the main reason for the end of therapy was confirmed progression (Supplementary Figure S1B). In total, 11 patients were not evaluated for any treatment response, including those who died before the first response evaluation. During the first three months of immunotherapy (i.e., at the time of sample collection), the next dose of ICI was postponed at least one time in 28 patients $(45.2 \%)$, and the median delay time was four days. The delay was usually due to the patient's condition, but sometimes due to medical-unrelated issues. For a few patients, the blood sample collection was disrupted as a result of the COVID-19 pandemic and hospital restrictions. Therefore, the number of samples coming from these patients was incomplete. In total, 249 blood samples were collected and used in the analyses. 
Table 1. Characteristics of NSCLC patients treated with anti-PD-1/PD-L1 agents.

\begin{tabular}{|c|c|c|c|c|}
\hline & All $(n=62)$ & $\operatorname{ATEZO}(n=42)$ & PEMBRO $(n=20)$ & $p$-Value \\
\hline - Age [years] & $65.4 \pm 7.2$ & $65.1 \pm 6.3$ & $66.2 \pm 8.9$ & NS \\
\hline - age $\geq 65$ & $37(59.7 \%)$ & $26(61.9 \%)$ & $11(55.0 \%)$ & NS \\
\hline - $\quad$ BMI $\left[\mathrm{kg} / \mathrm{m}^{2}\right]$ & $25.8 \pm 4.3$ & $26.4 \pm 4.3$ & $24.5 \pm 4.1$ & NS \\
\hline$-\quad$ BMI $\geq 25$ & $30(48.4 \%)$ & $21(50.0 \%)$ & $9(45.0 \%)$ & NS \\
\hline - missing information & $3(4.8 \%)$ & $3(7.1 \%)$ & $0(0.0 \%)$ & \\
\hline \multicolumn{5}{|l|}{ - Gender } \\
\hline - females & $25(40.3 \%)$ & $15(35.7 \%)$ & $10(50.0 \%)$ & \multirow{3}{*}{ NS } \\
\hline - males & $37(59.7 \%)$ & $27(64.3 \%)$ & $10(50.0 \%)$ & \\
\hline \multicolumn{4}{|l|}{ - Smoking status } & \\
\hline - never smoker & $7(11.3 \%)$ & $4(9.5 \%)$ & $3(15.0 \%)$ & \multirow{4}{*}{ NS } \\
\hline - former smoker & $39(62.9 \%)$ & $28(66.7 \%)$ & $11(55.0 \%)$ & \\
\hline - current smoker & $13(21.0 \%)$ & $7(16.7 \%)$ & $6(30.0 \%)$ & \\
\hline - missing information & $3(4.8 \%)$ & $3(7.1 \%)$ & $0(0.0 \%)$ & \\
\hline \multicolumn{5}{|l|}{ - Type of NSCLC } \\
\hline - ADC & $38(61.3 \%)$ & $27(64.3 \%)$ & $11(55.0 \%)$ & \multirow{3}{*}{ NS } \\
\hline - SQC & $19(30.6 \%)$ & $11(26.2 \%)$ & $8(40.0 \%)$ & \\
\hline - NOS/other/missing information & $5(8.1 \%)$ & $4(9.5 \%)$ & $1(5.0 \%)$ & \\
\hline \multicolumn{5}{|l|}{ - Stage of NSCLC } \\
\hline - III * & $2(3.2 \%)$ & $2(4.8 \%)$ & 0 & \multirow[t]{2}{*}{ NS } \\
\hline$-\quad$ IV & $60(96.8 \%)$ & $38(95.2 \%)$ & $20(100 \%)$ & \\
\hline \multicolumn{5}{|l|}{ - Best response to treatment $\#$} \\
\hline - $C R$ & 0 & 0 & 0 & \multirow{5}{*}{ NS } \\
\hline - $P R$ & $10(16.1 \%)$ & $4(9.5 \%)$ & $6(30.0 \%)$ & \\
\hline$-\mathrm{SD}$ & $26(41.9 \%)$ & $17(40.5 \%)$ & $9(45.0 \%)$ & \\
\hline - PD & $23(37.1 \%)$ & $18(42.8 \%)$ & $5(25.0 \%)$ & \\
\hline$-n / \mathrm{e}$ & $3(4.8 \%)$ & $3(7.1 \%)$ & 0 & \\
\hline
\end{tabular}

Continuous (normally distributed data) were expressed as mean $\pm \mathrm{sd}$, categorical data were expressed as $n(\%) ;{ }^{*}$ III B T4N2M0; ${ }^{*}$ death before the first treatment evaluation was considered PD. Abbreviations: ADC, adenocarcinoma; ATEZO, atezolizumab; BMI, body mass index; CR, complete response; $n$ /e, not evaluated; NOS, not otherwise specified; NS, not significant; NSCLC, non-small cell carcinoma; PD, progressive disease; PEMBRO, pembrolizumab; PR, partial response; SD, stable disease; SQC, squamous cell carcinoma.

\subsection{Samples and Methods}

The peripheral blood samples were centrifuged at $1700 \times g$ for $15 \mathrm{~min}$, aliquoted, and stored at $-80^{\circ} \mathrm{C}$ until use. Serum sCD25 was determined by the sandwich enzyme-linked immunosorbent assay (ThermoFisher Scientific, Waltham, MA, USA; Cat. No. BMS212-2), strictly according to the manufacturer's protocol. The optical density was read at $450 \mathrm{~nm}$ with reference $630 \mathrm{~nm}$ with the BioTek 800TS plate reader (BioTek Instruments, Winooski, VT, USA). Each sample was analyzed in duplicate. A log-log linear regression was used to calculate the SCD25 levels.

\subsection{Statistics}

All statistical analyses were performed with Statistica 13.3 software (Statsoft Inc., Tulsa, OK, USA). The Shapiro-Wilk test was used to check for normal distribution of continuous variables. Normally distributed data were then expressed as mean $\pm \mathrm{sd}$, while skewed data as median (interquartile range, IQR). Qualitative data were expressed as numbers and corresponding percentages. For between-group comparisons, the $t$-Student test, Mann-Whitney U test, Kruskal-Wallis test, or Chi-square test were used, as appropriate. The changes in biomarker levels over time compared to baseline were assessed with the Wilcoxon test. The Kaplan-Meier curves were used to check the associations between high and low protein levels and OS, PFS, and TTF. The differences between the curves were calculated with the log-rank test, and patients who did not experience the event of interest (death for OS analyses; progression or death for PFS analyses; treatment failure for TTF analyses) were censored in Kaplan-Meier analyses. Patients who stopped immunotherapy due to other reasons than progression or death were censored in PFS analyses unless they died within the three months after discontinuation of immunotherapy. Such an approach 
was necessary as these patients were lost to follow-up. The Cox proportional hazard models were used to confirm the prognostic role of the tested biomarkers on OS, PFS, and TTF. For all performed analyses, a $p$-value $<0.05$ was considered significant.

\section{Results}

\subsection{Kinetic Changes in Serum sCD25}

We started our analyses by testing how sCD25 levels changed after the start of immunotherapy. The sCD25 level increased after the first dose of ATEZO in all patients, and PEMBRO in $88.2 \%$ of patients. The relative change compared to baseline (sCD25.1/0 ratio) was $154.5 \%$ (136.6-205.3) in ATEZO and 147.7\% (119.5-208.2) in PEMBRO subgroup (medians (IQRs)). It was the highest increase in the sCD25 level during the first three months of immunotherapy in both groups (Figure 1A,B). We did not find any significant differences in SCD25 levels between patients dosed with ATEZO and PEMBRO at any of the evaluated time points. Therefore, further analyses were performed after combining these patients into one study group.

\section{ATEZO}

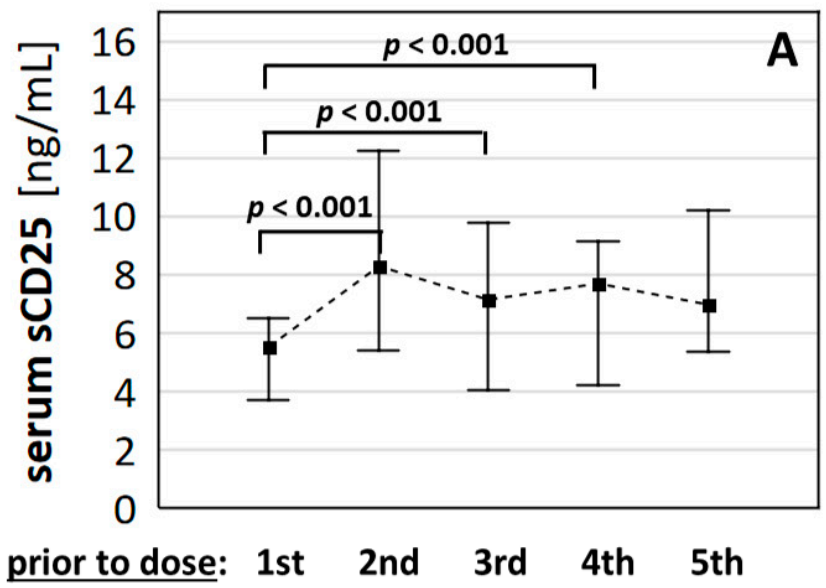

PEMBRO

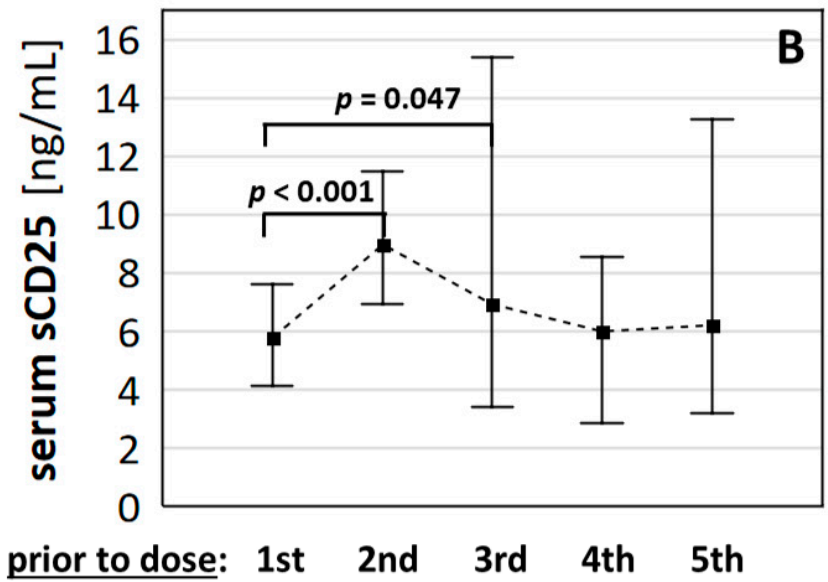

Figure 1. Changes in serum sC25 during the first four cycles of immunotherapy with anti-PD-1/PD-L1 drugs. Figure presents medians (filled squares) and interquartile ranges (whiskers) of sCD25 protein in subjects with NSCLC receiving (A) ATEZO and (B) PEMBRO.

\subsection{Association with Clinicodemographic Data}

The sCD25 levels and their changes were independent of the NSCLC subtype (Supplementary Figure S2), smoking status (Supplementary Figure S3), or BMI $<$ and $\geq 25 \mathrm{~kg} / \mathrm{m}^{2}$ (Supplementary Figure S4). Serum sCD25 did not differ significantly between females and males (Supplementary Figure S5A1-A5). However, the relative changes of sCD25 across therapy tended to be higher in females than males, and the difference reached significance for sCD25.1/0, sCD25.2/0, and sCD25.4/0 (Supplementary Figure S5B1-B4). Older patients $(\geq 65$ years old) presented a stronger increase in SCD25 levels at the end of cycle 1 (sCD25.1/0 ratio) (Supplementary Figure S6).

Due to revealed differences, further analyses were performed with sCD25 levels only (sCD25.0-sCD25.4), not with their relative changes compared to baseline (sCD25.1/0sCD25.4/0).

\subsection{Clinical Benefits 1-Year from the Start of Immunotherapy}

Baseline serum sCD25 concentrations (sCD25.0) were significantly lower in patients who presented disease control after twelve months from the start of immunotherapy (BEN-12 group) than in those with no benefits (NB-12 group): 4.50 (3.03-5.82) vs. 5.99 (4.45-7.64) ng/mL (Figure 2A). After the first dose of the anti-PD-1/PD-L1s, the sCD25 level increased significantly in both groups $(p<0.001$ from Wilcoxon test). However, it 
returned to baseline values only in BEN-12 group ( $p>0.05$ for sCD25.3 and sCD25.4 levels compared to baseline). The levels of sCD25 were significantly lower in BEN-12 than in NB-12 group at the end of cycle three (sCD25.3) and four (sCD25.4): 5.07 (2.67-6.58) vs. 7.89 (5.53-9.20) ng/mL for sCD25.3 (Figure 2D) and $3.92(2.38-6.85)$ vs. $7.73(6.05-11.83) \mathrm{ng} / \mathrm{mL}$ for sCD25.4 (Figure 2E).
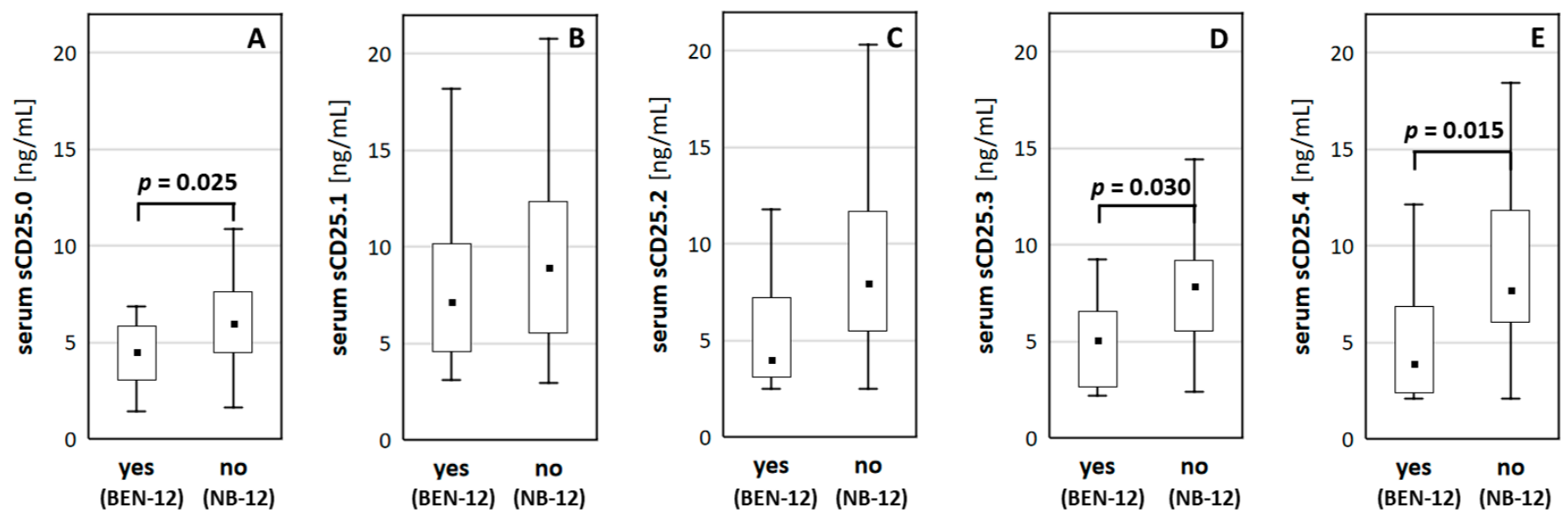

clinical benefits after 12 months from the start of immunotherapy

Figure 2. Serum sCD25 levels stratified by achieving long-term benefits from treatment. Figure presents medians (filled squares), interquartile ranges (boxes), and ranges excluding outliers for sCD25 protein measured at (A) baseline and at the end of (B) cycle 1, (C) cycle 2, (D) cycle 3, and (E) cycle 4 in patients who obtained (BEN-12) and lacked (NB-12) clinical benefits after 12 months from the start of immunotherapy.

\subsection{Survival Analyses}

Based on the previous analysis, levels of sCD25.0, sCD25.3, and sCD25.4 were chosen for survival analyses. The cut-offs were median values for patients without long-term benefits (assessed after twelve months from the initiation of therapy; NB-12 group). For biomarkers that differed significantly in the survival curves, Cox regression analysis was performed to account for other factors' influence.

The log-rank test indicated that sCD25 level was not predictive in terms of patient survival (OS). Patients stratified according to the sCD25.0 (cut-off: $5.99 \mathrm{ng} / \mathrm{mL}$ ) and $\mathrm{sCD} 25.4$ concentrations (cut-off: $7.73 \mathrm{ng} / \mathrm{mL}$ ) differed in TTF $(p=0.008$ and $p=0.013$ ) and PFS ( $p=0.019$ and $p=0.023$, respectively).

The median values for TTF in patients with low and high sCD25.0 were 6.0 and 3.1 months (Figure 3A1), and for PFS it was 6.3 and 3.1 months (Figure 3B1). A lack of short-term benefits from treatment was observed in $27.8 \%$ of patients with low and $57.7 \%$ of patients with high baseline sCD25 (Table 2). After a year, the therapy was continued by $36.1 \%$ of patients with low baseline and $7.7 \%$ of patients with high baseline sCD25 (Table 2).

The median values for TTF in patients with low and high sCD25.4 were 12.1 vs. 4.7 months, and for PFS it was 12.1 vs. 5.9 months. Three months from the start of therapy, a lack of clinical benefits from treatment was observed in $4.8 \%$ of patients with low and $42.9 \%$ of patients with high sCD25.4. The therapy was continued for at least a year by $42.9 \%$ of patients with low and $7.1 \%$ of patients with high sCD25.4 (Table 2).

Figure 3A2,B2 present the differences in TTF and PFS after stratifying patients by high and low levels of both sCD25.0 and sCD25.4. None of the patients with high sCD25.0 and sCD25.4 continued the therapy longer than 9.3 months; almost $40 \%$ of patients with low sCD25.0 and sCD25.4 were treated for at least 12.3 months (Figure 3A2).

The univariate Cox regression showed that PFS and TTF were independent on gender, administered drug, smoking status, age, BMI, and NSCLC subtype. High sCD25.0 $(\geq 5.99 \mathrm{ng} / \mathrm{mL}$ ) was a prognostic factor of shorter TTF (HR $=2.18,95 \%$ CI: $1.24-3.83$, 
$p=0.007)$ and PFS (HR $=2.06,95 \%$ CI: 1.14-3.74, $p=0.017)$; high sCD25.4 $(\geq 7.73 \mathrm{ng} / \mathrm{mL})$ was a prognostic factor of shorter TTF (HR $=2.93,95 \%$ CI: 1.34-6.40, $p=0.007)$ and PFS $(\mathrm{HR}=2.76,95 \% \mathrm{CI}: 1.22-6.23, p=0.014)$; high concentrations of both $\mathrm{sCD} 25.0(\geq 5.99 \mathrm{ng} / \mathrm{mL})$ and sCD25.4 $(\geq 7.73 \mathrm{ng} / \mathrm{mL})$ were a prognostic factor of shorter TTF $(\mathrm{HR}=4.18,95 \% \mathrm{CI}$ : $1.73-10.08, p=0.001)$ and PFS (HR $=3.90,95 \%$ CI: $1.56-9.76, p=0.004)$.
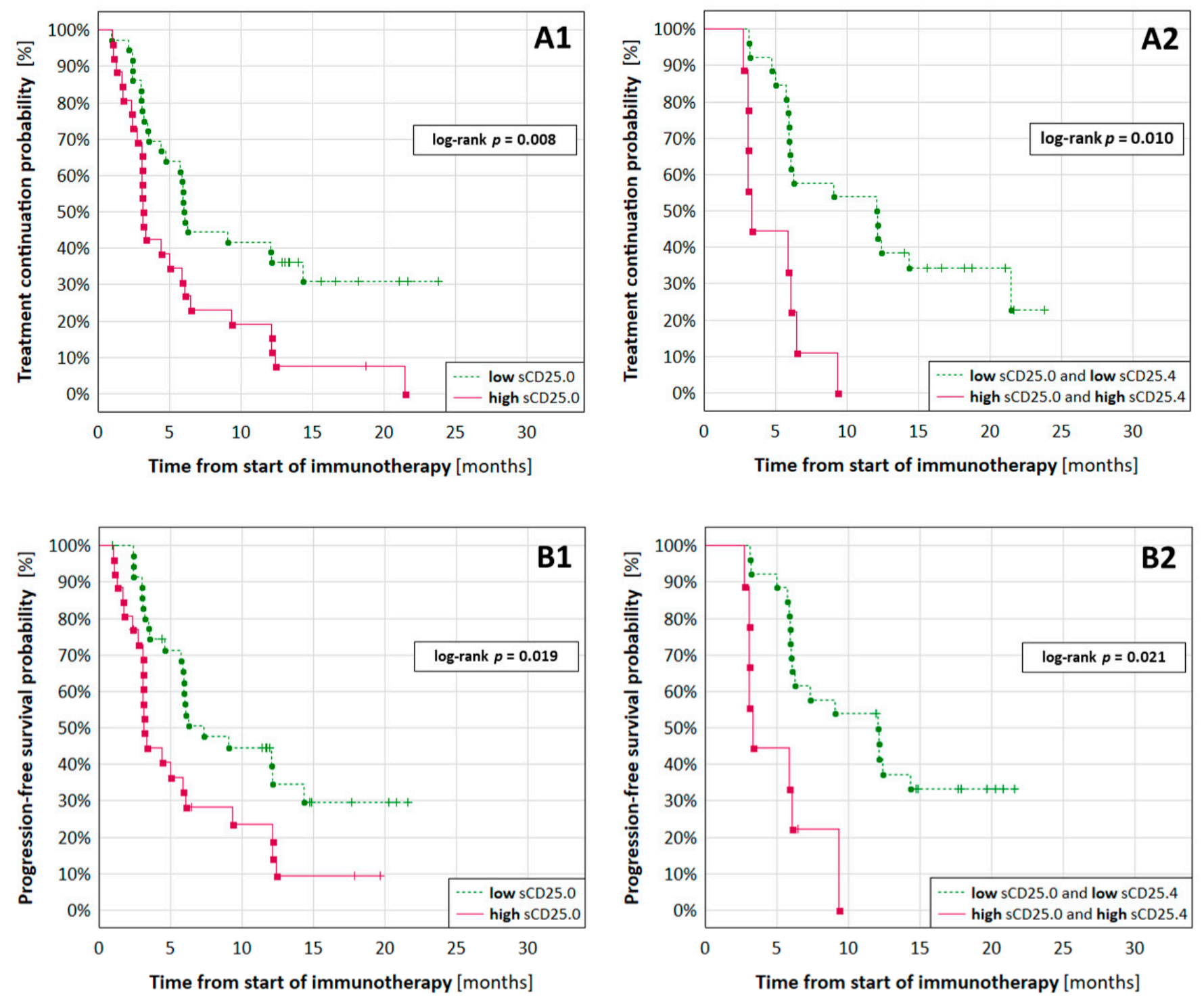

Figure 3. Kaplan-Meier curves for TTF and PFS based on the sCD25 levels. High sCD25.0 level ( $\geq 5.99 \mathrm{ng} / \mathrm{mL}) \mathrm{was}$ a prognostic factor of (A1) shorter TTF and (B1) shorter PFS; high sCD25.0 ( $\geq 5.99 \mathrm{ng} / \mathrm{mL})$ and sCD25.4 $(\geq 7.73 \mathrm{ng} / \mathrm{mL})$ levels were a prognostic factor of (A2) shorter TTF and (B2) shorter PFS in NSCLC patients dosed with ATEZO or PEMBRO; complete observations are denoted as filled circles, censored observations as crosses.

After stratifying patients by low and high levels of sCD25.0, sCD25.4 or both, betweengroup comparison with regard to patients' characteristics was additionally performed to confirm groups' similarity. Most patients with a low concentration of sCD25.0 were $\geq 65$ years old $(72.2 \%$ vs. $27.8 \%, p<0.05)$, and a similar trend was observed for a group with low both sCD25.0 and sCD25.4 (69.2\% vs. 30.8\%, $p=0.068)$. Moreover, in a high sCD25.0 level subgroup, there was a trend toward more males than females (73.1 vs. $26.9 \%$, $p=0.058$ ). No other between-group differences were observed (data not shown).

To account for these discrepancies, the multivariable Cox regression analysis was performed that included (1) age $\geq 65$ and gender and as the confounding factors in sCD25.0 
analyses and (2) age $\geq 65$ in the analyses including both sCD25.0 and sCD25.4. High $\mathrm{sCD} 25.0(\geq 5.99 \mathrm{ng} / \mathrm{mL})$ was an independent prognostic factor of shorter TTF (HR = 2.34, 95\% CI: $1.22-4.48, p=0.010$ ) and PFS (HR $=2.24,95 \%$ CI: $1.13-4.44, p=0.021$ ); high concentrations of both sCD25.0 $(\geq 5.99 \mathrm{ng} / \mathrm{mL})$ and sCD25.4 $(\geq 7.73 \mathrm{ng} / \mathrm{mL})$ were an independent prognostic factor of shorter TTF (HR $=6.33,95 \%$ CI: $2.10-19.06, p=0.001$ ) and PFS (HR $=6.50,95 \%$ CI: 2.04-20.73, $p=0.002$ ).

Table 2. Clinical benefits in NSCLC patients treated with ATEZO or PEMBRO.

\begin{tabular}{|c|c|c|c|c|c|c|c|}
\hline & & \multicolumn{3}{|c|}{$\begin{array}{c}\text { Clinical Benefits } \\
3 \text { Months from the Start of Treatment }\end{array}$} & \multicolumn{3}{|c|}{$\begin{array}{l}\text { Clinical Benefits } \\
12 \text { Months from the Start of Treatment }\end{array}$} \\
\hline & & Yes & No & $p$-Value & Yes & No & $p$-Value \\
\hline sCD25.0 & $\begin{array}{l}\text { low } \\
\text { high }\end{array}$ & $\begin{array}{c}26 \\
(72.2 \%) \\
11 \\
(42.3 \%)\end{array}$ & $\begin{array}{c}10 \\
(27.8 \%) \\
15 \\
(57.7 \%)\end{array}$ & $p<0.05$ & $\begin{array}{c}13 \\
(36.1 \%) \\
2 \\
(7.7 \%)\end{array}$ & $\begin{array}{c}23 \\
(63.9 \%) \\
24 \\
(92.3 \%)\end{array}$ & $p<0.05$ \\
\hline sCD25.4 & $\begin{array}{l}\text { low } \\
\text { high }\end{array}$ & $\begin{array}{c}20 \\
(95.2 \%) \\
8 \\
(57.1 \%)\end{array}$ & $\begin{array}{c}1 \\
(4.8 \%) \\
6 \\
(42.9 \%)\end{array}$ & $p<0.01$ & $\begin{array}{c}9 \\
(42.9 \%) \\
1 \\
(7.1 \%)\end{array}$ & $\begin{array}{c}12 \\
(57.1 \%) \\
13 \\
(92.9 \%)\end{array}$ & $p<0.05$ \\
\hline sCD25.0 \& sCD25.4 & $\begin{array}{l}\text { low } \\
\text { high }\end{array}$ & $\begin{array}{c}24 \\
(92.3 \%) \\
4 \\
(44.4 \%)\end{array}$ & $\begin{array}{c}2 \\
(7.7 \%) \\
5 \\
(55.6 \%)\end{array}$ & $p<0.01$ & $\begin{array}{c}10 \\
(38.5 \%) \\
0 \\
(0 \%)\end{array}$ & $\begin{array}{c}16 \\
(61.5 \%) \\
9 \\
(100 \%)\end{array}$ & $p<0.05$ \\
\hline
\end{tabular}

Results are presented as number of patients (\%); sCD25.0 (cut-off: $5.99 \mathrm{ng} / \mathrm{mL}$ ) and sCD25.4 (cut-off: $7.73 \mathrm{ng} / \mathrm{mL}$ ) levels of sCD25 at baseline and at the end of cycle four.

\section{Discussion}

ICIs have improved the treatment outcomes in various cancers, including NSCLC [4]. However, not all patients benefit from the therapy [6,36], which raises economic and ethical concerns. Here, we demonstrate that a high level of serum SCD25 could be a prognostic factor of lack of short and long-term benefits from treatment with ATEZO or PEMBRO. Patients with a high sCD25 level at baseline (sCD25.0) or/and at the end of the fourth cycle of drug dosing (sCD25.4) progressed faster and lived shorter without the disease progression and/or serious toxicity.

The sCD25 molecule has been studied for many years, mainly in conditions associated with the dysregulated immune system. Serum sCD25 is elevated in various autoimmune and inflammatory conditions but also in neoplastic diseases [21], including lung cancer. Several authors have reported higher levels of sCD25 in NSCLC [29,37-41], and our results are in line with these observations. Baseline sCD25 (sCD25.0) in our population was 5.62 $(3.72-6.88) \mathrm{ng} / \mathrm{mL}$ (median, IQR), while the literature data indicate the mean or median values for healthy volunteers was in the range of $0.45-3.83 \mathrm{ng} / \mathrm{mL}[39,42-44]$.

We did not find any significant differences in SCD25 levels between patients with ADC and SQC, which supports the observations presented by others [37-40]. The SCD25 levels were also independent on gender, though the relative changes in sCD25 compared to baseline were or tended to be higher in females than in males. Data from the literature show that while the sCD25 protein level is not affected by gender in healthy individuals $[45,46]$, it may be disease-specific [42]. Although some authors reported that serum sCD25 increased with age [27,46,47], others obtained contradictory results [22,42]. We observed no difference in baseline sCD25 between older and younger individuals. However, after the first dose of ICI, sCD25 level increased more in older ( $\geq 65$ years) than in younger patients ( $163.2 \mathrm{vs.}$ $137.8 \%, p<0.01)$. In general, serum sCD25 increased at the end of the first treatment cycle almost in all patients dosed with ATEZO or PEMBRO, and this agrees with the observations for other ICIs $[32,48]$. 
Reports about sCD25 and ICIs concern mostly CTLA-4-blockade and melanoma patients [32,33]. A study by Hannani and colleagues [32] revealed that higher baseline sCD25 predicted shorter OS in patients administered with ipilimumab. Similar conclusions were later presented by Bajor and colleagues [33] for concomitant therapy with tremelimumab and a CD40 agonist. We did not confirm the association between SCD25 values and OS in the study population. However, we demonstrated that the concentrations of sCD25 measured at selected time points during immunotherapy were significant predictors of TTF and PFS. One year after the start of the anti-PD-1/PD-L1 treatment, at least three times more NSCLC patients did not experience progression, and about four times more patients still continued therapy when their baseline sCD25 was low $(<5.99 \mathrm{ng} / \mathrm{mL})$. This corroborates with the results of Armand and colleagues [49], who reported poor response to NIVO (anti-PD-1) in patients with lymphoma and high baseline sCD25.

We also noticed that levels of sCD25 measured at the end of the fourth cycle of treatment (i.e., about three months from the start of immunotherapy) were predictive in terms of achieving clinical benefits. The relationship was even stronger when both time points were considered. All patients with high levels of sCD25.0 and sCD25.4 lacked longterm benefits, while almost $40 \%$ of patients with low levels achieved long-term benefits from treatment. Importantly, other authors highlighted a better response to the anti-PD-1 agents among NSCLC patients presenting higher IL-2 levels three months from the start of treatment [50]. Together, these observations support the hypothesis on the role of sCD25 as a decoy receptor for IL-2, favoring Tregs and tolerance induction and depriving effector T-cells of sufficient IL-2 [21].

Recently, Takai and colleagues [51] linked high levels of sCD25 with various immunerelated adverse events in patients with malignant diseases dosed with ICIs. Moreover, Yoshida and colleagues [52] showed that SCD25 predicted the occurrence and the disease activity of the checkpoint inhibitor pneumonitis in NSCLC. In our population, only a small number of patients experienced severe (at least grade 3) toxicity (Supplementary Figure S1B). Thus, we did not correlate serum sCD25 with the immune-related adverse events. However, we noticed that in survival analyses, high sCD25 levels usually impacted to a higher extent TTF than PFS, suggesting that not all patients with higher sCD25 levels discontinued therapy due to progression.

In the literature, there is no agreement on whether the sCD25 levels reflect disease progression in NSCLC. Most, but not all [29,53], studies have shown no differences in the concentrations of sCD25 between different stages of NSCLC $[38,39,41]$. We demonstrated that high baseline sCD25 predicted not only short (three months) but also long-term benefits from immunotherapy (twelve months). Therefore, worse outcomes in the high sCD25 level groups resulted more likely from the poor anti-PD-1/PD-L1 efficacy rather than disease progression. To our best knowledge, our study is the first one indicating SCD25 as a useful marker that could be easily measured and indicate patients with NSCLC who would not benefit from immunotherapy with ATEZO or PEMBRO. Worth noting is that we obtained a similar cut-off for baseline sCD25 $(5.99 \mathrm{ng} / \mathrm{mL})$ as Cabrera et al. [25] $(5.80 \mathrm{ng} / \mathrm{mL})$ and Wang et al. [22] (6.05 ng/mL), who found correlations between the elevated sCD25 levels and shorter OS or PFS in other types of cancers.

The source of the elevated SCD25 levels in NSCLC patients undergoing immunotherapy remains unclear. However, it is probably not derived from the tumor microenvironment. In patients with rare solid tumors, exposure to the anti-PD-1 agent resulted in decreased secretion of sIL-2R in CD8+ tumor-infiltrating lymphocytes [54]. The source of the sCD25 could be the tumor tissue. Indeed, Yano et al. [53] showed that lung cancer cells express CD25 antigen and may release its soluble form. Moreover, sCD25 might also be released from the activated peripheral T cells, e.g., Tregs [55]. In line with this hypothesis, in NSCLC, non-responders to PD-1 blockade presented a higher percentage of baseline CD25+FOXP3+CD4+ T cells [11].

The strengths of the project include its prospective character in terms of sample collection. We collected samples both prior to and after the start of immunotherapy, which 
allowed for assessing how the levels of sCD25 changed across the treatment. Moreover, all NSCLC patients were undergoing monotherapy with ATEZO or PEMBRO with the same dosing regimen. This allowed for better evaluation of how the anti-PD-1/PD-L1 drugs relate to the levels of sCD25 regardless of the other treatment options. The major limitation of our study is the small sample size. This project was a one-year pilot study conducted in one of the local hospitals. Therefore, the number of participants was relatively small. We aimed to assess whether the soluble sCD25 protein might have a predictive value in indicating patients who would benefit from immunotherapy, which could justify further studies. Additionally, the immunotherapy was temporarily discontinued in a few patients. Thus, the time between the next doses and sample collection sometimes exceeded 21 days. This interruption could affect the results but was impossible to avoid in real-world settings. Finally, though both drugs blocked the PD-1/PD-L1 pathway, PEMBRO was administered as a first-line treatment while ATEZO was administered as a second-line treatment. This discrepancy was due to eligibility criteria for the NSCLC drug program in Poland at the time of conducting the study (Supplementary Table S1).

\section{Conclusions}

To sum up, we demonstrated that high levels of serum sCD25 protein at baseline and three months from the start of immunotherapy could easily and quickly identify NSCLC patients who would not achieve long-term benefits from ATEZO or PEMBRO treatment. This observation supports the hypothesis on the benefits from monitoring anticancer therapy with serum sCD25 [21].

Supplementary Materials: The following are available online at https:/ /www.mdpi.com/article/10 $.3390 /$ cancers13153702/s1: Figure S1, (A) Time to treatment failure and (B) reason for ending the anti-PD-1/PD-L1 treatment in patients with non-small cell lung carcinoma dosed with atezolizumab or pembrolizumab; Figure S2, Serum SCD25 levels and their relative changes stratified by NSCLC subtype; Figure S3, Serum sCD25 levels and their relative changes stratified by smoking status; Figure S4, Serum sCD25 levels and their relative changes stratified by BMI; Figure S5, Serum sCD25 levels and their relative changes stratified by gender; Figure S6, Serum SCD25 levels and their relative changes stratified by age; Table S1, Eligibility criteria for treatment with ATEZO or PEMBRO, according to the NSCLC drug program in Poland at the time of conducting the study.

Author Contributions: Conceptualization, A.S.; methodology, A.S. and F.K.G.; software, A.S.; validation, K.K.-N.; formal analysis, A.S., K.K.-N., and J.T.; investigation, A.S., M.B., K.K.-N., and J.T.; resources, A.S., M.B., I.G.-G., and A.B.-W.; data curation, A.S., M.B., and K.K.-N.; writing-original draft preparation, A.S.; writing—review and editing, A.S., K.K.-N., and F.K.G.; visualization, A.S.; supervision, M.B., F.K.G.; project administration, A.S., M.B., and F.K.G.; funding acquisition, A.S. All authors have read and agreed to the published version of the manuscript.

Funding: This research was funded by the National Science Center in Poland (Narodowe Centrum Nauki), grant number 2019/03/X/NZ6/00406.

Institutional Review Board Statement: The study was conducted in accordance with the Declaration of Helsinki and the approval of the Bioethics Committee at Poznan University of Medical Sciences (decision no. 80/19 and 251/19).

Informed Consent Statement: Written informed consent was obtained from all subjects involved in the study.

Data Availability Statement: All data relevant to the article were included in the manuscript and presented as Tables and Figures, or were provided as Supplementary Materials. Additional data are available upon reasonable request from the corresponding author.

Acknowledgments: We would like to thank all the patients and hospital staff who contributed to the project. We also appreciate help of Christine Yohn from the Department of Pharmaceutics at Rutgers University for her contribution in the English revision of the manuscript.

Conflicts of Interest: A.S. received a grant from the National Science Center in Poland (2019/03/X/ NZ6/00406) during the conduct of the study; M.B. reports personal fees from Hoffmann La Roche, 
Astra Zeneca, Boehringer-Ingelheim, MSD, BMS, and Pfizer outside the submitted work; J.T. reports personal fees from GlaxoSmithKline outside the submitted work; K.K.-N., I.G.-G., A.B.-W., and F.K.G. disclosed no conflicts of interests. The funders had no role in the design of the study, in the collection, analyses, or interpretation of data, in the writing of the manuscript, or in the decision to publish the results.

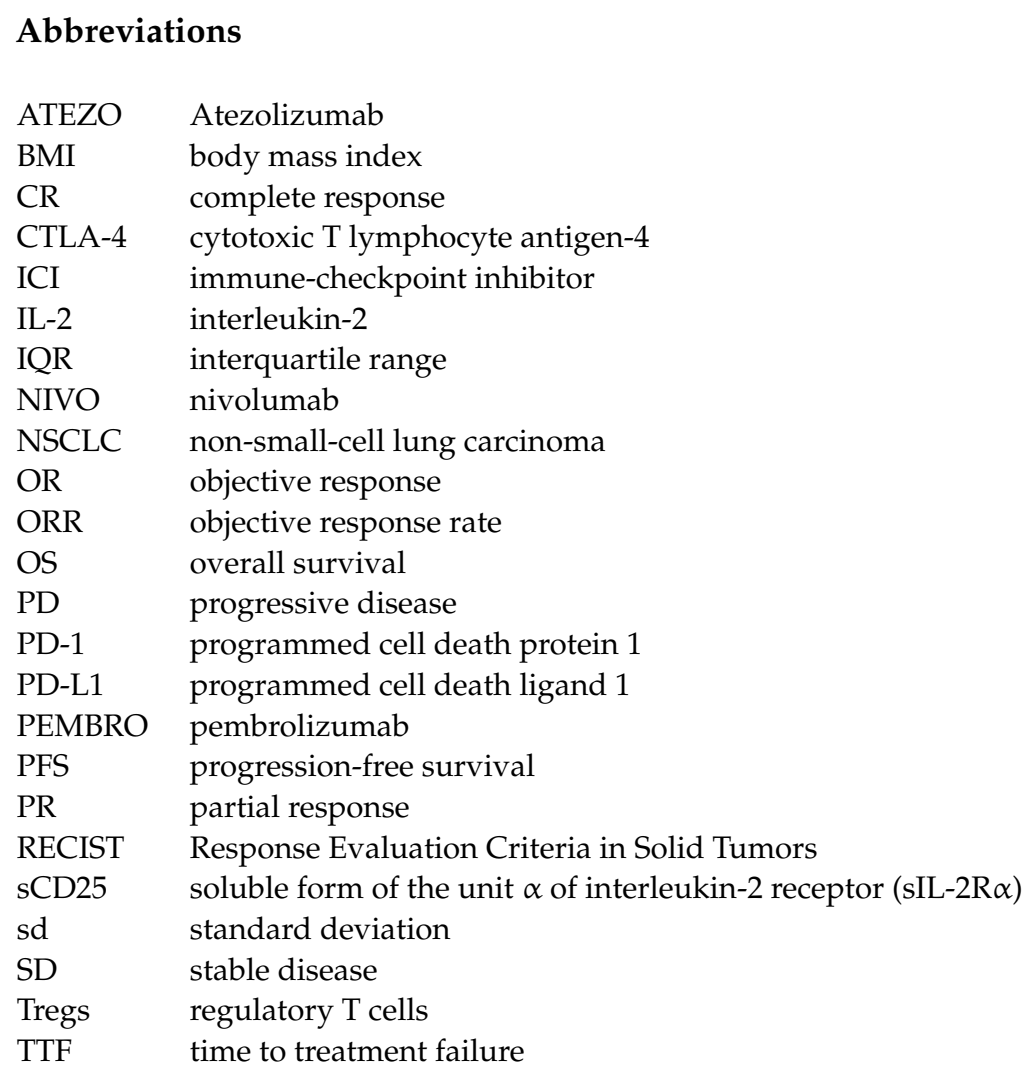

\section{References}

1. American Cancer Society-Information and Resources for Cancer: Breast, Colon, Lung, Prostate, Skin. Available online: https:/ / www.cancer.org (accessed on 7 November 2020).

2. De Angelis, R.; Sant, M.; Coleman, M.P.; Francisci, S.; Baili, P.; Pierannunzio, D.; Trama, A.; Visser, O.; Brenner, H.; Ardanaz, E.; et al. Cancer Survival in Europe 1999-2007 by Country and Age: Results of EUROCARE-5-A Population-Based Study. Lancet Oncol. 2014, 15, 23-34. [CrossRef]

3. Howlader, N.; Noone, A.; Krapcho, M.; Garshell, J.; Neyman, N.; Altekruse, S.; Kosary, C.; Yu, M.; Ruhl, J.; Tatalovich, Z.; et al. SEER Cancer Statistics Review, 1975-2010, National Cancer Institute. Available online: https://seer.cancer.gov/archive/csr/1975 _2010/index.html. (accessed on 7 November 2020).

4. Doroshow, D.B.; Sanmamed, M.F.; Hastings, K.; Politi, K.; Rimm, D.L.; Chen, L.; Melero, I.; Schalper, K.A.; Herbst, R.S. Immunotherapy in Non-Small Cell Lung Cancer: Facts and Hopes. Clin. Cancer Res. 2019, 25, 4592-4602. [CrossRef]

5. Grigg, C.; Rizvi, N.A. PD-L1 Biomarker Testing for Non-Small Cell Lung Cancer: Truth or Fiction? J. Immunother. Cancer 2016, 4, 48. [CrossRef]

6. Sun, L.; Zhang, L.; Yu, J.; Zhang, Y.; Pang, X.; Ma, C.; Shen, M.; Ruan, S.; Wasan, H.S.; Qiu, S. Clinical Efficacy and Safety of Anti-PD-1/PD-L1 Inhibitors for the Treatment of Advanced or Metastatic Cancer: A Systematic Review and Meta-Analysis. Sci. Rep. 2020, 10, 2083. [CrossRef]

7. Von Pawel, J.; Bordoni, R.; Satouchi, M.; Fehrenbacher, L.; Cobo, M.; Han, J.Y.; Hida, T.; Moro-Sibilot, D.; Conkling, P.; Gandara, D.R.; et al. Long-Term Survival in Patients with Advanced Non-Small-Cell Lung Cancer Treated with Atezolizumab versus Docetaxel: Results from the Randomised Phase III OAK Study. Eur. J. Cancer 2019, 107, 124-132. [CrossRef]

8. Zimmermann, S.; Peters, S.; Owinokoko, T.; Gadgeel, S.M. Immune Checkpoint Inhibitors in the Management of Lung Cancer. Am. Soc. Clin. Oncol. Educ. Book 2018, 38, 682-695. [CrossRef] [PubMed]

9. Luo, J.; Bandlamudi, C.; Ricciuti, B.; Vokes, N.; Schoenfeld, A.J.; Egger, J.V.; Sauter, J.L.; Plodkowski, A.J.; Preeshagul, I.R.; Kris, M.G.; et al. Long-Term Responders to PD-1 Blockade in Patients with Advanced Non-Small Cell Lung Cancer (NSCLC). J. Clin. Oncol. 2020, 38, 9549. [CrossRef] 
10. Jo, H.; Yoshida, T.; Yagishita, S.; Shinno, Y.; Okuma, Y.; Goto, Y.; Horinouchi, H.; Yamamoto, N.; Ohe, Y. The Characteristics of Long-Lasting Responders to PD-1 Inhibitor in Advanced Non-Small Cell Lung Cancer Patients. Ann. Oncol. 2019, 30, xi27. [CrossRef]

11. Kagamu, H.; Kitano, S.; Yamaguchi, O.; Yoshimura, K.; Horimoto, K.; Kitazawa, M.; Fukui, K.; Shiono, A.; Mouri, A.; Nishihara, F.; et al. CD4+ T-Cell Immunity in the Peripheral Blood Correlates with Response to Anti-PD-1 Therapy. Cancer Immunol. Res. 2019, 8, 334-344. [CrossRef]

12. Riella, L.V.; Paterson, A.M.; Sharpe, A.H.; Chandraker, A. Role of the PD-1 Pathway in the Immune Response. Am. J. Transpl. 2012, 12, 2575-2587. [CrossRef]

13. Antonia, S.J.; Borghaei, H.; Ramalingam, S.S.; Horn, L.; Carpeño, J.D.C.; Pluzanski, A.; Burgio, M.A.; Garassino, M.; Chow, L.Q.M.; Gettinger, S.; et al. Four-Year Survival with Nivolumab in Patients with Previously Treated Advanced Non-Small-Cell Lung Cancer: A Pooled Analysis. Lancet Oncol. 2019, 20, 1395-1408. [CrossRef]

14. Bhaijee, F.; Anders, R.A. PD-L1 Expression as a Predictive Biomarker: Is Absence of Proof the Same as Proof of Absence? JAMA Oncol. 2016, 2, 54-55. [CrossRef]

15. Haragan, A.; Field, J.K.; Davies, M.P.A.; Escriu, C.; Gruver, A.; Gosney, J.R. Heterogeneity of PD-L1 Expression in Non-Small Cell Lung Cancer: Implications for Specimen Sampling in Predicting Treatment Response. Lung Cancer 2019, 134, 79-84. [CrossRef] [PubMed]

16. Niu, M.; Yi, M.; Li, N.; Luo, S.; Wu, K. Predictive Biomarkers of Anti-PD-1/PD-L1 Therapy in NSCLC. Exp. Hematol. Oncol. 2021, 10, 18. [CrossRef]

17. Galvano, A.; Gristina, V.; Malapelle, U.; Pisapia, P.; Pepe, F.; Barraco, N.; Castiglia, M.; Perez, A.; Rolfo, C.; Troncone, G.; et al. The Prognostic Impact of Tumor Mutational Burden (TMB) in the First-Line Management of Advanced Non-Oncogene Addicted Non-Small-Cell Lung Cancer (NSCLC): A Systematic Review and Meta-Analysis of Randomized Controlled Trials. ESMO Open 2021, 6, 100124. [CrossRef] [PubMed]

18. Zhang, N.; Jiang, J.; Tang, S.; Sun, G. Predictive Value of Neutrophil-Lymphocyte Ratio and Platelet-Lymphocyte Ratio in Non-Small Cell Lung Cancer Patients Treated with Immune Checkpoint Inhibitors: A Meta-Analysis. Int. Immunopharmacol. 2020, 85, 106677. [CrossRef] [PubMed]

19. Zhang, R.J.; Zhang, X.; Chen, J.; Shao, M.; Yang, Y.; Balaubramaniam, B.; Sun, X.L.; Ambrus, J.L.; He, J.; Li, Z.G. Serum Soluble CD25 as a Risk Factor of Renal Impairment in Systemic Lupus Erythematosus-A Prospective Cohort Study. Lupus 2018, 27, 1100-1106. [CrossRef]

20. Brusko, T.M.; Wasserfall, C.H.; Hulme, M.A.; Cabrera, R.; Schatz, D.; Atkinson, M.A. Influence of Membrane CD25 Stability on T Lymphocyte Activity: Implications for Immunoregulation. PLoS ONE 2009, 4, e7980. [CrossRef]

21. Damoiseaux, J. The IL-2-IL-2 Receptor Pathway in Health and Disease: The Role of the Soluble IL-2 Receptor. Clin. Immunol. 2020, 218, 108515. [CrossRef]

22. Wang, L.; Wang, J.-H.; Liu, W.-J.; Wang, W.; Wang, H.; Chen, X.-Q.; Geng, Q.-R.; Lu, Y.; Xia, Z.-J. High Level of Soluble Interleukin2 Receptor in Serum Predicts Treatment Resistance and Poor Progression-Free Survival in Multiple Myeloma. Ann. Hematol. 2017, 96, 2079-2088. [CrossRef]

23. Dlouhy, I.; Filella, X.; Rovira, J.; Magnano, L.; Rivas-Delgado, A.; Baumann, T.; Martínez-Trillos, A.; Balagué, O.; Martínez, A.; González-Farre, B.; et al. High Serum Levels of Soluble Interleukin-2 Receptor (SIL2-R), Interleukin-6 (IL-6) and Tumor Necrosis Factor Alpha (TNF) Are Associated with Adverse Clinical Features and Predict Poor Outcome in Diffuse Large B-Cell Lymphoma. Leuk. Res. 2017, 59, 20-25. [CrossRef] [PubMed]

24. Gross, M.; Meirovich, A.; Rachmut, J.; Kalichman, I.; Peretz, T.; Eliashar, R.; Barak, V. The Diagnostic and Prognostic Value of SIL-2R as an Immune Biomarker in Head and Neck Cancers. Anticancer Res. 2016, 36, 4347-4352. [PubMed]

25. Cabrera, R.; Ararat, M.; Cao, M.; Xu, Y.; Wasserfall, C.; Atkinson, M.A.; Liu, C.; Nelson, D.R. Hepatocellular Carcinoma Immunopathogenesis: Clinical Evidence for Global T Cell Defects and an Immunomodulatory Role for Soluble CD25 (SCD25). Dig. Dis. Sci. 2010, 55, 484-495. [CrossRef] [PubMed]

26. Nukui, A.; Masuda, A.; Abe, H.; Arai, K.; Yoshida, K.-I.; Kamai, T. Increased Serum Level of Soluble Interleukin-2 Receptor Is Associated with a Worse Response of Metastatic Clear Cell Renal Cell Carcinoma to Interferon Alpha and Sequential VEGFTargeting Therapy. BMC Cancer 2017, 17, 372. [CrossRef]

27. Wang, L.-S.; Chow, K.-C.; Li, W.-Y.; Liu, C.-C.; Wu, Y.-C.; Huang, M.-H. Clinical Significance of Serum Soluble Interleukin 2 Receptor- $\alpha$ in Esophageal Squamous Cell Carcinoma. Clin. Cancer Res. 2000, 6, 1445-1451.

28. Brunetti, G.; Bossi, A.; Baiardi, P.; Jedrychowska, I.; Pozzi, U.; Bacchella, L.; Bernardo, G. Soluble Interleukin 2 Receptor (SIL2R) in Monitoring Advanced Lung Cancer during Chemotherapy. Lung Cancer 1999, 23, 1-9. [CrossRef]

29. De Vita, F.; Turitto, G.; di Grazia, M.; Frattolillo, A.; Catalano, G. Analysis of Interleukin-2/Interleukin-2 Receptor System in Advanced Non-Small-Cell Lung Cancer. Tumori J. 1998, 84, 33-38. [CrossRef]

30. Tisi, E.; Lissoni, P.; Angeli, M.; Arrigoni, C.; Corno, E.; Cassina, E.; Ballabio, D.; Benenti, C.; Barni, S.; Tancini, G. Postoperative Increase in Soluble Interleukin-2 Receptor Serum Levels as Predictor for Early Recurrence in Non-Small Cell Lung Carcinoma. Cancer 1992, 69, 2458-2462. [CrossRef]

31. Cabrera, R.; Ararat, M.; Eksioglu, E.A.; Cao, M.; Xu, Y.; Wasserfall, C.; Atkinson, M.A.; Liu, C.; Nelson, D.R. Influence of Serum and Soluble CD25 (SCD25) on Regulatory and Effector T-Cell Function in Hepatocellular Carcinoma. Scand. J. Immunol. 2010, 72, 293-301. [CrossRef] [PubMed] 
32. Hannani, D.; Vétizou, M.; Enot, D.; Rusakiewicz, S.; Chaput, N.; Klatzmann, D.; Desbois, M.; Jacquelot, N.; Vimond, N.; Chouaib, S.; et al. Anticancer Immunotherapy by CTLA-4 Blockade: Obligatory Contribution of IL-2 Receptors and Negative Prognostic Impact of Soluble CD25. Cell Res. 2015, 25, 208-224. [CrossRef]

33. Bajor, D.L.; Mick, R.; Riese, M.J.; Huang, A.C.; Sullivan, B.; Richman, L.P.; Torigian, D.A.; George, S.M.; Stelekati, E.; Chen, F.; et al. Long-Term Outcomes of a Phase I Study of Agonist CD40 Antibody and CTLA-4 Blockade in Patients with Metastatic Melanoma. Oncoimmunology 2018, 7, e1468956. [CrossRef] [PubMed]

34. Eisenhauer, E.A.; Therasse, P.; Bogaerts, J.; Schwartz, L.H.; Sargent, D.; Ford, R.; Dancey, J.; Arbuck, S.; Gwyther, S.; Mooney, M.; et al. New Response Evaluation Criteria in Solid Tumours: Revised RECIST Guideline (Version 1.1). Eur. J. Cancer 2009, 45, 228-247. [CrossRef] [PubMed]

35. Centers for Disease Control and Prevention Tobacco Use Information-Glossary. Available online: https://www.cdc.gov/nchs/ nhis/tobacco/tobacco_glossary.htm (accessed on 30 April 2021).

36. Li, S.; Zhang, C.; Pang, G.; Wang, P. Emerging Blood-Based Biomarkers for Predicting Response to Checkpoint Immunotherapy in Non-Small-Cell Lung Cancer. Front. Immunol. 2020, 11, 603157. [CrossRef]

37. Vibe-Petersen, J.; Tvede, N.; Diamant, M.; Kjerulff, A.A.; Sørensen, H.R.; Andersen, V. Soluble Interleukin-2 Receptor and Soluble CD8 Antigen Levels in Serum from Patients with Non-Resectable Lung Cancer. Cancer Immunol. Immunother. 1991, 33, 121-127. [CrossRef]

38. Orditura, M.; De Vita, F.; Roscigno, A.; Auriemma, A.; Infusino, S.; Catalano, G. Soluble Interleukin-2 Receptor and Soluble CD8 Antigen Levels in Serum from Patients with Solid Tumors. Int. J. Mol. Med. 1998, 2, 75-79. [CrossRef] [PubMed]

39. Kaminska, J.; Kowalska, M.; Kotowicz, B.; Fuksiewicz, M.; Glogowski, M.; Wojcik, E.; Chechlinska, M.; Steffen, J. Pretreatment Serum Levels of Cytokines and Cytokine Receptors in Patients with Non-Small Cell Lung Cancer, and Correlations with Clinicopathological Features and Prognosis. M-CSF-An Independent Prognostic Factor. Oncology 2006, 70, 115-125. [CrossRef]

40. Kanazawa, S.; Yamaguchi, K.; Kinoshita, Y.; Komiyama, Y.; Muramatsu, M.; Nomura, S. Elevation of Soluble Interleukin-2 Receptor in Patients with Non-Small Cell Lung Cancer Treated with Gefitinib. J. Cancer Res. Clin. Oncol. 2006, 132, 719-725. [CrossRef]

41. Naumnik, W.; Chyczewska, E.; Kovalchuk, O.; Tałałaj, J.; Izycki, T.; Panek, B. Serum Levels of Interleukin-18 (IL-18) and Soluble Interleukin-2 Receptor (SIL-2R) in Lung Cancer. Rocz. Akad. Med. Bialymst. 2004, 49, 246-251. [PubMed]

42. Bharwani, K.D.; Dirckx, M.; Stronks, D.L.; Dik, W.A.; Schreurs, M.W.J.; Huygen, F.J.P.M. Elevated Plasma Levels of SIL-2R in Complex Regional Pain Syndrome: A Pathogenic Role for T-Lymphocytes? Mediat. Inflamm. 2017, 2017, 2764261. [CrossRef]

43. Bai, Y.-M.; Chiou, W.-F.; Su, T.-P.; Li, C.-T.; Chen, M.-H. Pro-Inflammatory Cytokine Associated with Somatic and Pain Symptoms in Depression. J. Affect. Disord. 2014, 155, 28-34. [CrossRef]

44. Sobjanek, M.; Bien, E.; Zablotna, M.; Sokolowska-Wojdylo, M.; Sikorska, M.; Lange, M.; Nowicki, R. Soluble Interleukin-2 Receptor $\alpha$ and Interleukin-2 Serum Levels in Patients with Basal Cell Carcinoma. Postepy Derm. Alergol. 2016, 33, 263-268. [CrossRef]

45. Gotoh, Y.; Okamoto, Y.; Uemura, O.; Mori, N.; Tanaka, S.; Ando, T.; Nishida, M. Determination of Age-Related Changes in Human Soluble Interleukin 2 Receptor in Body Fluids of Normal Subjects as a Control Value against Disease States. Clin. Chim. Acta 1999, 289, 89-97. [CrossRef]

46. Motojima, S.; Hirata, A.; Fukuda, T.; Makino, S. High Serum Soluble Interleukin-2 Receptor Concentrations in Elderly Individuals and Smokers. Arerugi 1993, 42, 1715-1720.

47. Durda, P.; Sabourin, J.; Lange, E.M.; Nalls, M.A.; Mychaleckyj, J.C.; Jenny, N.S.; Li, J.; Walston, J.; Harris, T.B.; Psaty, B.M.; et al. Plasma Levels of Soluble Interleukin-2 Receptor $\alpha$ : Associations with Clinical Cardiovascular Events and Genome-Wide Association Scan. Arterioscler. Thromb. Vasc. Biol. 2015, 35, 2246-2253. [CrossRef]

48. Das, R.; Verma, R.; Sznol, M.; Boddupalli, C.S.; Gettinger, S.N.; Kluger, H.; Callahan, M.; Wolchok, J.D.; Halaban, R.; Dhodapkar, M.V.; et al. Combination Therapy with Anti-CTLA-4 and Anti-PD-1 Leads to Distinct Immunologic Changes in Vivo. J. Immunol. 2015, 194, 950-959. [CrossRef]

49. Armand, P.; Janssens, A.M.; Gritti, G.; Radford, J.; Timmerman, J.M.; Pinto, A.; Vilchez, S.M.; Johnson, P.W.M.; Cunningham, D.; Leonard, J.P.; et al. Efficacy and Safety Results from CheckMate 140, a Phase 2 Study of Nivolumab for Relapsed/Refractory Follicular Lymphoma. Blood 2020, 137, 637-645. [CrossRef]

50. Boutsikou, E.; Domvri, K.; Hardavella, G.; Tsiouda, D.; Zarogoulidis, K.; Kontakiotis, T. Tumour Necrosis Factor, InterferonGamma and Interleukins as Predictive Markers of Antiprogrammed Cell-Death Protein-1 Treatment in Advanced Non-Small Cell Lung Cancer: A Pragmatic Approach in Clinical Practice. Adv. Med. Oncol. 2018, 10, 1758835918768238. [CrossRef]

51. Takai, R.; Funakoshi, Y.; Suto, H.; Nagatani, Y.; Imamura, Y.; Toyoda, M.; Yakushijin, K.; Kiyota, N.; Harada, K.-I.; Yamashita, K.; et al. Serum Soluble Interleukin-2 Receptor as a Potential Biomarker for Immune-Related Adverse Events. Anticancer Res. 2021, 41, 1021-1026. [CrossRef]

52. Yoshida, K.; Morishima, Y.; Shiozawa, T.; Nakazawa, K.; Matsuyama, M.; Kiwamoto, T.; Matsuno, Y.; Sekine, I.; Hizawa, N. Serum Soluble Interleukin-2 Receptor as a Possible Biomarker for the Early Detection and Follow-up of Nivolumab-Induced Pneumonitis. J. Thorac. Oncol. 2019, 14, e90-e91. [CrossRef]

53. Yano, T.; Fukuyama, Y.; Yokoyama, H.; Takai, E.; Tanaka, Y.; Asoh, H.; Ichinose, Y. Interleukin-2 Receptors in Pulmonary Adenocarcinoma Tissue. Lung Cancer 1996, 16, 13-19. [CrossRef] 
54. Creasy, C.A.; Forget, M.-A.; Singh, G.; Tapia, C.; Xu, M.; Stephen, B.; Sabir, S.; Meric-Bernstam, F.; Haymaker, C.; Bernatchez, C.; et al. Exposure to Anti-PD-1 Causes Functional Differences in Tumor-Infiltrating Lymphocytes in Rare Solid Tumors. Eur. J. Immunol. 2019, 49, 2245-2251. [CrossRef] [PubMed]

55. Pedersen, A.E.; Lauritsen, J.P. CD25 Shedding by Human Natural Occurring CD4+CD25+ Regulatory T Cells Does Not Inhibit the Action of IL-2. Scand. J. Immunol. 2009, 70, 40-43. [CrossRef] [PubMed] 